\title{
PERSEPSI TENAGA MEDIS DAN PARAMEDIS TERHADAP PASIEN MENINGGAL DI RS PKU MUHAMMADIYAH GOMBONG
}

\author{
Abdul Hakim Nitiprodjo ${ }^{1}$, Andi Muhammad Maulana ${ }^{1}$ \\ ${ }^{1}$ Fakultas Kedokteran, Universitas Muhammadiyah Purwokerto
}

\begin{abstract}
ABSTRAK
Latar belakang: Seorang dokter pasti akan dihadapkan pada kasus kematian dalam melaksanakan profesinya. Di Rumah Sakit, dari hasil pengamatan dokter dan perawat, pasien ditandai dengan pupil midriasis, berhentinya denyut jantung dan pernafasan dianggap telah meninggal dunia atau mati secara klinis. Dalam waktu kurang dari satu jam bahkan kurang dari 30 menit, pasien yang meninggal baik di Instalasi Gawat Darurat, rawat inap, ICU dipindahkan ke Kamar Jenazah. Tindakan tersebut bukan berarti tidak menimbulkan perdebatan, karena adanya kemungkinan bahwa pasien hanya mati suri.

Tujuan: Mengamati persepsi tenaga medis dan paramedis terhadap pasien meninggal di Rumah Sakit dalam menentukan diagnosa kematian.

Metode: Jenis penelitian ini merupakan penelitian deskriptif kualitatif. Populasi yang diteliti adalah dokter dan perawat di RS PKU Muhammadiyah Gombong. Sampel yang digunakan adalah dokter jaga dan perawat yang bertugas di Instalasi Gawat Darurat, ruang Rawat Inap, dan ruang Intensive Care Unit (ICU). Pengambilan sampel dilakukan dengan metode judgmental sampling. Jumlah sampel penelitian diambil $20 \%$ dari total sampel yang ada di RS PKU Muhammadiyah Gombong.

Hasil: Terdapat variasi persepsi di antara ketiga dokter mengenai pasien yang dinyatakan meninggal, dua dari tiga dokter memeriksa tanda pasti kematian pada pasien. Terdapat variasi persepsi mengenai pasien yang dinyatakan meninggal dari 37 perawat yang dikelompokkan menjadi tujuh grup sesuai dengan pernyataannya masing - masing, enam dari tujuh grup memeriksa tanda pasti kematian pada pasien.

Kesimpulan: Terdapat variasi persepsi tenaga medis dan paramedis terhadap pasien yang meninggal di Rumah Sakit PKU Muhammadiyah Gombong. Sebagian besar dokter dan perawat telah menerapkan thanatologi dalam mendiagnosa kematian yang pasti pada pasien.
\end{abstract}

Kata Kunci: Kematian, persepsi, tenaga medis, paramedis

\section{ABSTRACT}

Background: A doctor will certainly be faced with the death case in carrying out his profession. At the Hospital, from the observations of doctors and nurses, patients signed with midriasis pupils, cardiac arrest and respiration are thought to have died or died clinically. In less than an hour or less than 30 minutes, patients who died either at Emergency Installation, inpatient, ICU were transferred to the Mortuary. The action doesn't mean it doesn't cause a debate, because of the possibility that the patient is only suspended animation.

Objectives: Observing the perceptions of medical personnel and paramedics on patients died at the hospital in determining the diagnosis of death.

Methods: This type of research is qualitative descriptive research. The population studied were doctors and nurses at PKU Muhammadiyah Gombong Hospital. The samples used were physician and nurse who served in Emergency Installation, Inpatient Room, and Intensive Care Unit (ICU) of PKU Muhammadiyah Gombong Hospital. Sampling is done by judgmental sampling method (sampling technique). The number of research samples taken $20 \%$ of the total sample in RS PKU Muhammadiyah Gombong.

Results: There were variations of perception among the three doctors regarding the deceased patient, two from three doctors examining the exact signs of death in the patient. There were variations in perception of deceased patients from 37 nurses who were grouped into seven groups according to their respective statements, six of the seven groups examined the exact signs of death in patients.

Conclusion: There are variations in perceptions of medical personnel and paramedics on patients who died at PKU Muhammadiyah Gombong Hospital. Most doctors and nurses have applied the therapies to diagnose definite death in patients.

Keywords: Death, perception, medical personnel, paramedics 


\section{PENDAHULUAN}

Seorang dokter pasti akan dihadapkan pada kasus kematian dalam melaksanakan profesinya. Kematian merupakan proses akhir kehidupan makhluk hidup yang ditandai minimal dengan berhentinya tiga sistem, yaitu sistem pernafasan, sirkulasi (pendarahan), dan persarafan. Dengan berhentinya ketiga sistem tersebut, maka seseorang dapat dianggap sudah meninggal. ${ }^{1}$

Di Rumah Sakit, dari hasil pengamatan dokter dan perawat, pasien yang ditandai dengan pupil midriasis, berhentinya denyut jantung dan pernafasan dianggap telah meninggal dunia atau mati secara klinis. Dalam waktu kurang dari satu jam bahkan kurang dari 30 menit, pasien yang meninggal baik di Instalasi Gawat Darurat, rawat inap, ICU (Intensive Care Unit) dipindahkan ke Instalasi Pemulasaraan Jenazah. Tindakan tersebut bukan berarti tidak menimbulkan perdebatan, karena adanya kemungkinan bahwa pasien hanya mati suri. Waktu yang diperlukan untuk menimbulkan tanda pasti kematian minimal sekitar satu hingga dua jam pasca mati klinis. ${ }^{1}$

Di salah satu Rumah Sakit yang ada di wilayah Kabupaten Kebumen, ditemukan salah satu kejadian yang menunjukkan adanya dugaan bahwa pasien anak sempat hidup kembali setelah dinyatakan meninggal. Ibu pasien dan salah satu petugas pemulasaraan jenazah mendengar suara mengeluh dari pasien anak tersebut yang sudah ditutup tubuhnya dengan kain putih. Ibu dan petugas panik mendengar suara tersebut. Walau demikian, tidak sampai menimbulkan perdebatan hebat antara ibu pasien dengan petugas. ${ }^{1}$

Pengetahuan tentang forensik dan medikolegal tenaga medis dan paramedis yang mencakup aspek kematian atau meninggalnya seorang pasien di Pelayanan Kesehatan terutama di Rumah Sakit perlu diamati. Dari uraian di atas dapat dirumuskan masalah yaitu: Bagaimana persepsi tenaga medis dan paramedis terhadap pasien meninggal di Rumah Sakit dalam menentukan diagnosa kematian?

Penelitian ini bertujuan untuk mengamati persepsi tenaga medis dan paramedis terhadap pasien meninggal di Rumah Sakit dalam menentukan diagnosa kematian.

Thanatologi berasal dari dua kata, yaitu "thanatos yang berarti mati dan "logos" yang berarti ilmu. Thanatologi adalah ilmu yang mempelajari segala macam aspek yang berkaitan dengan mati yang meliputi pengertian, cara-cara melakukan diagnosis, perubahan-perubahan yang terjadi sesudah mati dan manfaatnya. Manusia menurut ilmu kedokteran memiliki dua dimensi, yaitu sebagai individu dan sebagai kumpulan dari berbagai macam sel. Oleh sebab itu kematian manusia juga dapat dilihat dari kedua dimensi, dengan catatan bahwa kematian sel akibat ketiadaan oksigen baru 
akan terjadi setelah kematian manusia sebagai individu atau kematian somatik ${ }^{2}$.

Mati mempunyai dua stadium yaitu: somatic death/ systemic death dan cellular death/molecular death. Kedua stadium ini menggambarkan tahapan proses kematian seseorang.

Dalam stadium somatic death, fungsi pernafasan dan peredaran darah telah berhenti, sehingga terjadi anoksia yang lengkap dan menyeluruh dalam jaringan-jaringan. Akibatnya proses aerobik dalam sel-sel berhenti, sedangkan proses anaerobik masih berlangsung. Tanda- tanda kematian yang dapat diperiksa dalam stadium somatic death adalah: hilangnya pergerakan dan sensibilitas, berhentinya pernafasan, dan berhentinya denyut jantung dan peredaran darah.

Dalam stadium cellular death baru timbul tanda-tanda kematian pasti, yaitu: menurunnya suhu mayat (algor mortis), lebam mayat (livor mortis), kaku mayat (rigor mortis), perubahan pada kulit dan mata, dan proses pembusukan dan modifikasinya seperti mummifikasi dan adiposera ${ }^{3}$.

Lebam mayat atau livor mortis terjadinya karena adanya gaya gravitasi yang menyebabkan darah mengumpul pada bagian-bagian tubuh terendah dan bebas dari tekanan dimana sesuai posisi tubuh mayat ${ }^{4}$. Awalnya darah mengumpul pada vena-vena besar dan kemudian pada cabangcabangnya sehingga mengakibatkan perubahan warna kulit menjadi merah kebiruan ${ }^{5}$. Timbulnya lebam mayat antara 1 sampai 2 jam setelah mati. Pada orang yang menderita anemia atau perdarahan timbulnya lebam mayat menjadi lebih lama, sedangkan pada orang yang mati akibat penyakit lama timbulnya lebam mayat lebih cepat ${ }^{6}$. Lokalisasinya pada bagian terendah dari tubuh mayat, kecuali pada bagian tubuh yang tertekan. Pada posisi terlentang lebam mayat dapat ditemukan pada tengkuk atau leher bagian belakang, punggung, bokong dan bagian fleksor dari anggota gerak bawah ${ }^{2}$. Lebam mayat menetap setelah 8-12 jam pasca kematian ${ }^{7}$.

Kaku mayat atau rigor mortis terjadi akibat proses biokimiawi, yaitu pemecahan ATP menjadi ADP. Selama masih ada P (phosphokreatinase) berenergi tinggi dari pemecahan glikogen otot, maka ADP masih dapat diresintesis menjadi ATP kembali ${ }^{5}$. Jika persediaan glikogen otot habis, maka resintesis tidak terjadi sehingga terjadi penumpukan ADP yang akan mengakibatkan otot menjadi kaku. Otot-otot tidak dapat berkontraksi meskipun dirangsang secara mekanik maupun elektrik. Otot-otot tidak dapat berkontraksi meskipun dirangsang secara mekanik maupun elektrik ${ }^{2}$. Kaku mayat mulai timbul minimal 1 jam setelah meninggal dan mulai menghilang 18 jam setelah meninggal.

Pembusukan yang terjadi pada tubuh mayat disebabkan oleh proses autolisis dan aktivitas mikroorganisme. Proses autolisis terjadi sebagai 
akibat dari pengaruh enzim yang dilepaskan oleh selsel yang sudah mati. Mula-mula yang terkena ialah nucleoprotein yang terdapat pada kromatin dan sesudah itu sitoplasma. Dinding sel akan mengalami kehancuran dan akibatnya jaringan akan menjadi lunak. Proses autolisis ini tidak dipengaruhi oleh mikroorganisme dan oleh sebab itu pada mayat yang bebas hama, misalnya mayat bayi dalam kandungan, proses autolisis tetap berlangsung ${ }^{2}$.

Mengenai mikroorganisme penyebab pembusukan, yang paling utama ialah kuman Clostridium welchii yang umumnya terdapat pada usus besar. Karena pada orang yang sudah mati semua sistem pertahanan tubuh hilang maka kumankuman pembusuk tersebut dapat leluasa memasuki pembuluh darah dan menggunakan darah sebagai media untuk berkembang biak ${ }^{8}$. Proses pembusukan mulai tampak antara $24-48$ jam sesudah mati.

Persepsi adalah suatu proses penggunaan pengetahuan yang telah dimiliki (yang disimpan di dalam ingatan) untuk mendeteksi atau memperoleh dan menginterpretasi stimulus yang diterima oleh alat indera seperti mata, telinga dan hidung. Persepsi merupakan suatu proses menginterpretasi atau menafsirkan informasi yang diperoleh melalui sistem alat manusia. Sebagai contoh, pada waktu seseorang membaca tulisan, melihat sebuah gambar, mendengarkan suara tertentu, ia akan melakukan interpretasi berdasarkan pengetahuan yang dimilikinya dan yang relevan dengan hal-hal itu?

Persepsi ialah memberikan makna pada stimulus inderawi ${ }^{10}$.

Pengertian tenaga medis adalah seorang yang memiliki kemampuan menangani pasien secara medis dan profesional serta telah menyelesaikan pendidikan baik di fakultas kedokteran maupun fakultas kedokteran gigi. Tenaga medis yang dimaksud adalah dokter atau para ahli kedokteran yang mempunyai spesialisasi di bidangnya. Sedangkan pengertian paramedis adalah seorang dalam bidang kesehatan yang membantu dokter menangani dan merawat pasien. Contoh paramedis adalah perawat, mantri, bidan, teknisi ambulans. Dalam hal ini, peneliti membatasi paramedis pada perawat.

\section{METODE}

Penelitian ini dilaksanakan pada bulan Januari 2018 di Rumah Sakit PKU Muhammadiyah Gombong Kecamatan Gombong, Kabupaten Kebumen. Jenis penelitian ini merupakan penelitian deskriptif kualitatif. Peneliti hanya melakukan deskripsi mengenai fenomena yang ditentukan ${ }^{11}$. Rancangan penelitian ini untuk membuktikan apakah pemahaman petugas medis dan paramedis terhadap pasien yang meninggal memiliki persepsi yang berbeda. Populasi yang diteliti adalah dokter dan perawat di RS PKU Muhammadiyah Gombong. Sampel yang digunakan adalah dokter jaga dan perawat yang bertugas di Instalasi Gawat Darurat, ruang Rawat Inap, dan 
ruang Intensive Care Unit (ICU) RS PKU

Muhammadiyah Gombong. Pengambilan sampel dilakukan dengan metode judgmental sampling (teknik sampling). Jumlah sampel penelitian diambil $20 \%$ dari total sampel yang ada di RS PKU Muhammadiyah Gombong. Pengumpulan data dilakukan dengan menyebarkan kuesioner.

\section{HASIL DAN PEMBAHASAN}

Jumlah sampel penelitian sebanyak 40 sampel dari jumlah total dokter dan perawat sebanyak 197 orang yang ada di RS PKU Muhammadiyah Gombong. 40 sampel terdiri dari 3 dokter jaga dan 37 perawat. Parameter untuk kuesioner yang digunakan dalam penelitian ini adalah: berhentinya denyut jantung, berhentinya pernafasan, pupil dilatasi maksimal yang menetap, lebam mayat, kaku mayat, penurunan suhu tubuh mayat, dan pembusukan mayat. Berikut ini adalah data dari hasil kuesioner dokter jaga dan perawat:

Tabel 1. Hasil Kuesioner Dokter Jaga

\begin{tabular}{|c|l|}
\hline Profesi & \multicolumn{1}{|c|}{ Temuan pada pasien yang } \\
\hline Dokter A & $\begin{array}{l}\text { Berhentinya denyut jantung dan } \\
\text { pernafasan, pupil dilatasi maksimal }\end{array}$ \\
\hline Dokter B & $\begin{array}{l}\text { Berhentinya denyut jantung dan } \\
\text { pernafasan, pupil dilatasi maksimal }\end{array}$ \\
\hline Dokter C & Berhentinya denyut jantung dan \\
\hline
\end{tabular}

Dari hasil kuesioner di atas, terdapat variasi atau perbedaan persepsi di antara ketiga dokter mengenai pasien yang dinyatakan meninggal. Dua dari tiga dokter $(66,67 \%)$ memeriksa tanda pasti kematian pada pasien. Dokter A melakukan pemeriksaan adanya lebam mayat dan kaku mayat pada pasien. Dokter B hanya melakukan pemeriksaan adanya penurunan suhu tubuh mayat. Dapat dikatakan bahwa dokter A dan B juga memiliki persepsi yang berbeda khususnya tanda pasti kematian pada pasien. Walaupun penerapan thanatologi oleh dokter A dan B berbeda, dokter A dan B melakukan observasi terhadap pasien meninggal selama satu hingga dua jam untuk menemukan tanda-tanda pasti kematian. Sedangkan dokter C tidak memeriksa tanda pasti kematian pada pasien yang meninggal, maka kemungkinan pasien yang ditangani oleh dokter $\mathrm{C}$ tidak dilakukan observasi selama satu hingga dua jam setelah mati klinis. Dapat dikatakan, ketiga dokter memiliki perbedaan interpretasi terhadap suatu obyek.

Tabel 2. Hasil Kuesioner Perawat

\begin{tabular}{|l|c|l|}
\hline \multicolumn{1}{|c|}{ Profesi } & Jumlah & \multicolumn{1}{|c|}{$\begin{array}{c}\text { Temuan pada } \\
\text { pasien yang }\end{array}$} \\
\hline Perawat grup A & 5 & $\begin{array}{l}\text { Berhentinya denyut } \\
\text { jantung dan }\end{array}$ \\
\hline Perawat grup B & 1 & $\begin{array}{l}\text { Berhentinya denyut } \\
\text { jantung dan }\end{array}$ \\
\hline Perawat grup C & 8 & $\begin{array}{l}\text { Berhentinya denyut } \\
\text { jantung dan }\end{array}$ \\
\hline Perawat grup D & 1 & Berhentinya denyut \\
\hline Perawat grup E & 1 & $\begin{array}{l}\text { Berhentinya denyut } \\
\text { jantung dan }\end{array}$ \\
\hline Perawat grup F & 7 & $\begin{array}{l}\text { Berhentinya denyut } \\
\text { jantung dan }\end{array}$ \\
\hline Perawat grup G & 4 & $\begin{array}{l}\text { Berhentinya denyut } \\
\text { jantung dan }\end{array}$ \\
\hline
\end{tabular}

Dari hasil kuesioner di atas, terdapat variasi

atau perbedaan persepsi mengenai pasien yang dinyatakan meninggal dari 37 perawat yang 
dikelompokkan menjadi tujuh grup sesuai dengan pernyataannya masing - masing. Pernyataan perawat grup D tidak memeriksa tanda-tanda pasti kematian, sedangkan pernyataan perawat grup lainnya $(70,27 \%)$ memeriksa tanda-tanda pasti kematian. Pada perawat grup D, kemungkinan pasien yang ditanganinya tidak dilakukan observasi selama satu hingga dua jam setelah mati klinis. Sedangkan perawat grup lainnya, pasien yang meninggal secara klinis dilakukan observasi selama satu hingga dua jam untuk menemukan tanda-tanda pasti kematian. Pernyataan perawat dari keenam grup lainnya masing- masing memiliki persepsi yang berbeda khususnya tanda pasti kematian pada pasien. Penerapan thanatologi oleh grup-grup tersebut juga berbeda sesuai dengan pengetahuan yang telah dimilikinya.

Banyaknya perawat yang melakukan observasi tanda-tanda pasti kematian pada pasien yang meninggal di Rumah Sakit PKU Muhammadiyah Gombong dapat disebabkan perawat bersama dokter umum telah mendapatkan bimbingan dan pelatihan mengenai thanatologi oleh dokter ahli yang berpraktek di Rumah Sakit tersebut.

Dokter dan perawat Rumah Sakit PKU Muhammadiyah Gombong sebagian besar telah memeriksa tanda-tanda pasti kematian dan sebagian kecil tidak memeriksa tanda-tanda pasti kematian pada pasien yang dianggap sudah meninggal.
Semakin banyak dokter dan perawat memeriksa tanda-tanda pasti kematian pasien, maka resiko terjadinya kesalahan diagnosis pasien meninggal atau timbulnya kesan mati suri pada pasien semakin berkurang.

\section{SIMPULAN DAN SARAN}

Simpulan:

- Terdapat variasi persepsi tenaga medis dan paramedis terhadap pasien yang meninggal di Rumah Sakit PKU Muhammadiyah Gombong.

- Sebagian besar dokter dan perawat telah menerapkan thanatologi dalam mendiagnosa kematian yang pasti pada pasien.

Saran:

- Agar penelitian dapat berjalan lebih baik, maka perlu koordinasi yang maksimal antara peneliti dengan para dokter jaga sebagai salah satu subyek penelitian agar jumlah dokter jaga yang terlibat dalam penelitian lebih memadai dan dapat memperoleh hasil penelitian yang lebih tepat.

- Penelitian ini dapat dikembangkan untuk penelitian selanjutnya, berkaitan dengan persepsi tenaga kesehatan terhadap pasien meninggal yang terbagi sebelum dan setelah diberikan pelatihan thanatologi oleh dokter ahli. 


\section{DAFTAR PUSTAKA}

1. Siti M. 2017. Kutipan Tanya Jawab dengan Petugas Bina Rohani RS PKU Muhammadiyah Gombong.

2. Dahlan, Sofwan. 2007. Ilmu Kedokteran Forensik, Pedoman Bagi Dokter dan Penegak Hukum. Badan Penerbit Universitas Diponegoro, Semarang

3. Hoediyanto dan Hariadi A. 2010. Buku Ajar Ilmu Kedokteran Forensik dan Medikolegal: Thanatologi. Fakultas Kedokteran Universitas Airlangga, Surabaya

4. Idries, A., M., Agung L.. 2013. Penerapan Ilmu Kedokteran Forensik dalam Proses Penyidikan. CV Sagung Seto, Jakarta

5. Suharto, Gatot, dkk. 2010. Tanya Jawab Ilmu Kedokteran Forensik: Thanatologi, EdisiKedua. Badan Penerbit Universitas Diponegoro, Semarang

6. Kumar, V. et al. 1997. Basic Pathology, 6th Ed. WB Saunders Company, Philadelphia

7. Budiyanto, Arif, dkk. 1997. Ilmu Kedokteran Forensik, Cetakan Kedua. Bagian Kedokteran Forensik Fakultas Kedokteran Universitas Indonesia, Jakarta

8. Di Maio, Vincent J. 2007. Forensic Pathology, Second Edition. CRC Press, Florida

9. Suharnan. 2005. Psikologi Kognitif. Penerbit Srikandi, Surabaya

10. Rakhmat, Jalaluddin. 2013. Psikologi Komunikasi. PT Remaja Rosdakarya, Bandung

11. Sastroasmoro, Sudigdo dan Sofyan Ismael. 2008. Dasar-dasar Metodologi Penelitian Klinis, Edisi Ketiga. Penerbit CV Sagung Seto, Jakarta 